\title{
DA ETNOMATEMÁTICA AO ENSINO DE MATEMÁTICA: UMA ABORDAGEM A PARTIR DE LAKATOS
}

\author{
Ismael Batista Maidana Silvestre ${ }^{1}$; Marcos Alexandre Alves ${ }^{2}$
}

\section{RESUMO}

O artigo apresenta o pensamento de Lakatos, que é considerado um dos epistemólogos mais importantes do século XX e suas concepções teóricas têm cada vez mais implicações no ensino de ciências e matemática. As suas duas principais obras "Metodologia dos Programas de Pesquisa Científica" e "A Lógica do Descobrimento Matemático: Provas e Refutações" são citadas com frequência em trabalhos científicos. Apresenta-se uma breve revisão bibliográfica das concepções Lakatosianas, mais especificamente sobre as duas obras mencionadas acima, e as aproximações com metodologias (teorias) do ensino de matemática: Investigação Matemática e Etnomatemática. Tanto a Investigação Matemática como a Etnomatemática são caracterizadas como programas de pesquisa lakatosianos. Além disso, a abordagem metodológica utilizada na investigação matemática apresenta convergências com 0 processo utilizado na obra " $A$ Lógica do Descobrimento Matemático: Provas e Refutações".

PALAVRAS-CHAVE: Ensino; Etnomatemática; Investigação Matemática; Metodologia; Programas de Pesquisa.

Eixo Temático: Educação, Cultura e Comunicação (ECC).

\section{INTRODUÇÃO}

No momento em que esse trabalho é escrito, ainda está se enfrentando as dificuldades no ensino impostas pela pandemia do covid-19, em que milhares de estudantes acabaram por abandonar a escola, outros sem acesso aos meios tecnológicos e em situações precárias esforçam-se para cumprir as tarefas escolares. A pandemia também escancarou a necessidade que a educação precisa evoluir: Inserir tecnologias no ensino, mas oportunizar acesso a todos, a escola ser vista como um espaço de construção coletiva e humana - utilizando as diferenças como fonte de aprendizagem, e a busca incessante por metodologias de ensino que

\footnotetext{
${ }_{1}^{1}$ Doutorando em Ensino de Ciências e Matemática - UFN. E-mail: ismael.silvestre@ufn.edu.br

2 Doutor em Filosofia da Educação. Professor no Curso de Doutorado em Ensino de Ciências e Matemática - UFN. maralexalves@gmail.com
} 
oportunizem a participação efetiva dos alunos no processo de ensino e aprendizagem.

Pesquisadores em educação, em particular, os do ensino de matemática, têm desenvolvido muitos trabalhos utilizando diferentes metodologias, dentre elas as chamadas metodologias ativas.

Metodologia ativa é um processo de ensinagem ${ }^{3}$ dialógico, aberto, ativo e participativo que, por meio da curiosidade, da problematização, da relação teoria/prática, da significação, da co-reflexão, da utilização das TICs e da elaboração da síntese do conhecimento, objetiva resoluções de problemas e situações, construção do conhecimento e da autonomia e formação da cidadania, na qual o estudante autogerencia seu aprendizado, tendo o docente como instigador e mediador (FERREIRA; MOROSINI, 2019, p.5).

Diante dessa definição, pode-se considerar a investigação matemática e as concepções metodológicas da etnomatemática como metodologias ativas. Nesse trabalho, o objetivo será mostrar algumas aproximações entre a filosofia lakatosiana, mais especificamente no que tange a Metodologia dos programas de pesquisa científica e a obra A Lógica do Descobrimento Matemático: Provas e Refutações, e suas implicações/aproximações com a investigação matemática e a etnomatemática.

\section{Lakatos: Metodologia dos Programas de Pesquisa Científica}

Imre Lipschitz, de família judia, nasceu em 9 de novembro de 1922 na cidade de Decebren na Hungria. Em 1944, graduou-se em Matemática, Filosofia e Física na Universidade de Debrecen. Foi um atuante defensor da causa comunista, liderando grupos de estudos para jovens. Mudou seu sobrenome para Molnar e, mais tarde, para o que hoje é comumente conhecido, Lakatos (que significa serralheiro, em húngaro). Essas mudanças foram tentativas para fugir de perseguições nazistas durante a Segunda Grande Guerra.

Logo após o término da guerra, Lakatos ocupou um posto no Ministério da Educação húngaro, no entanto, suas ambições desagradaram ao partido comunista o que o levou a prisão entre os anos de 1950 e 1953. Passado esse período,

\footnotetext{
${ }^{3}$ Expressão usada para indicar uma prática social complexa efetivada entre os sujeitos, professor e aluno, englobando tanto a ação de ensinar quanto a de apreender, em processo contratual, de parceria deliberada e consciente para o enfrentamento na construção do conhecimento escolar, resultante de ações efetivadas na, e fora da sala de aula" (ANASTASIOU, 2005, p. 3).
} 
trabalhou como tradutor de textos de matemática para o húngaro, nessa então que teve a oportunidade de traduzir How to solve $i^{4}{ }^{4}$ de George Polya e também, conheceu a obra de Karl Popper.

Em 1956, com a revolta húngara contra o regime soviético, Lakatos fugiu para a Inglaterra. Doutorou-se em Filosofia na Universidade de Cambridge em 1956, e sua tese abordou a conjectura de Descartes-Euler, intitulada Ensaios na lógica da descoberta matemática. Em 1960, foi nomeado professor da London School of Economics (LSE), e nessa época trabalhou junto ao Popper. Permaneceu como professor e pesquisador na LSA até sua morte em 1974.

Escreveu ensaios e palestras sobre a Filosofia da Ciência e da Matemática. Organizou e publicou, com Alan Musgrave, as Atas do Seminário Internacional sobre Filosofia da Ciência, ocorrido em 1965, em quatro volumes: Problems in the Philosophy of Mathematics (v.1, 1967); Problems of Inductive Logic (v.2, 1968); Problems in the Philosophy of Science (v.3, 1968); Criticism and the Growth of Knowledge (v.4, 1969). Este último foi publicado no Brasil com o título $A$ Crítica e o Desenvolvimento do Conhecimento (LAKATOS; MUSGRAVE, 1979) e traz um artigo de Lakatos - O Falseamento e a Metodologia dos Programas de Pesquisa Científica - muito citado entre filósofos da Ciência e da Matemática. A maior parte das obras de Lakatos foram publicadas após sua morte e John Worrall, Gregory Currie e Elie Zahar são alguns dos principais responsáveis pelas revisões e organizações.

Worrall e Zahar foram os responsáveis por organizar a publicar a obra $A$ Lógica do Descobrimento Matemático: Provas e Refutações em 1976 pela Cambridge University Press, Londres. Já no Brasil, foi publicada em 1978 (LAKATOS, 1978). Essa obra traz a tese de doutorado do Lakatos com algumas interferências dos editores. Entre as obras de Lakatos, podem-se destacar essa que tem por base sua tese doutoral e a já citada A Crítica e o Desenvolvimento do Conhecimento.

A LSE instituiu o prêmio Lakatos em sua homenagem que é dado anualmente, desde o ano de 1986, para uma contribuição excepcional à filosofia da ciência. A contribuição precisa estar no formato de livro, ter sido publicada em até

\footnotetext{
${ }^{4}$ Traduzida e publicada no Brasil como A Arte de Resolver Problemas (1986).
} 
seis anos anteriores ao ano da premiação e em língua inglesa. O valor do prêmio é de dez mil libras esterlinas. Os livros premiados dão uma ideia do que tem sido pesquisado em filosofia da ciência nas últimas décadas.

Na obra A Crítica e o Desenvolvimento do Conhecimento, que contém as opiniões de importantes epistemólogos sobre as estruturas das revoluções científicas, tem um capítulo escrito por Lakatos: O Falseamento e a Metodologia dos Programas de Pesquisa Científica. Esse capítulo aborda o processo de desenvolvimento do conhecimento científico defendendo uma metodologia racional, com base na teoria de falseamento de Popper. Além disso, faz críticas a teoria de Thomas Khun.

Um programa de pesquisa é caracterizado por seu "núcleo firme": teoria ou conjunção de hipóteses contra a qual não é aplicada a "retransmissão da falsidade" 5 . "O núcleo firme é 'convencionalmente' aceito (e, portanto, 'irrefutável' por decisão provisória)" (Lakatos, 1983; p. 116). No entorno, com o objetivo de proteger o núcleo, tem-se o "cinturão protetor": constituído por hipóteses e teorias auxiliares "sobre cuja base se estabelecem as condições iniciais" (Lakatos, 1989; p.230) - e também pelos métodos observacionais. Ele protege o "núcleo firme", sendo constantemente modificado, expandido, complicado. Na Figura 1 é apresentada uma ilustração.

Figura 1: Base de um Programa de Pesquisa Científico, segundo Lakatos.

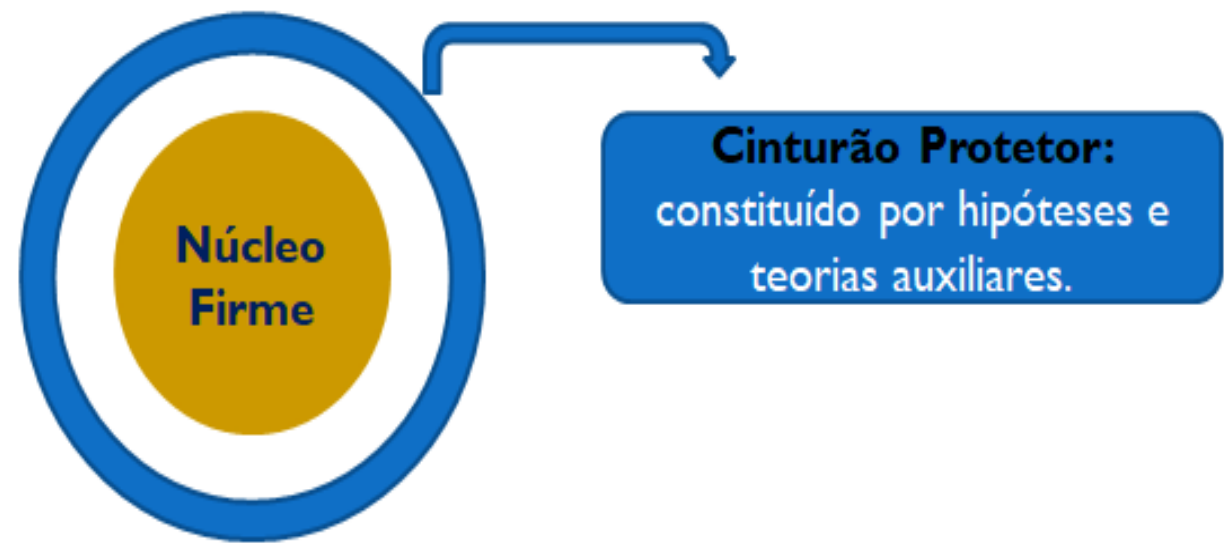

Fonte: Autor

\footnotetext{
${ }^{5}$ Em uma situação onde a consequência lógica de um conjunto de hipóteses é dada como falsa, a lógica dedutiva permite afiançar a falsidade de uma hipótese, ou de algumas hipóteses; essa é a "retransmissão da falsidade".
} 
Um exemplo muito utilizado é o programa de pesquisa de Newton. Seu "núcleo firme" continha as três leis do movimento e a Lei da Gravitação Universal e no "cinturão protetor" estavam: modelos do sistema solar, a forma e a distribuição de massa dos planetas e satélites, a ótica geométrica, a teoria sobre a refração da luz na atmosfera, etc (SILVEIRA, 1996; p. 221). A figura 2 ilustra o programa de pesquisa de Newton.

Figura 2: Programa de Newton com algumas Teorias Auxiliares no Cinturão Protetor.

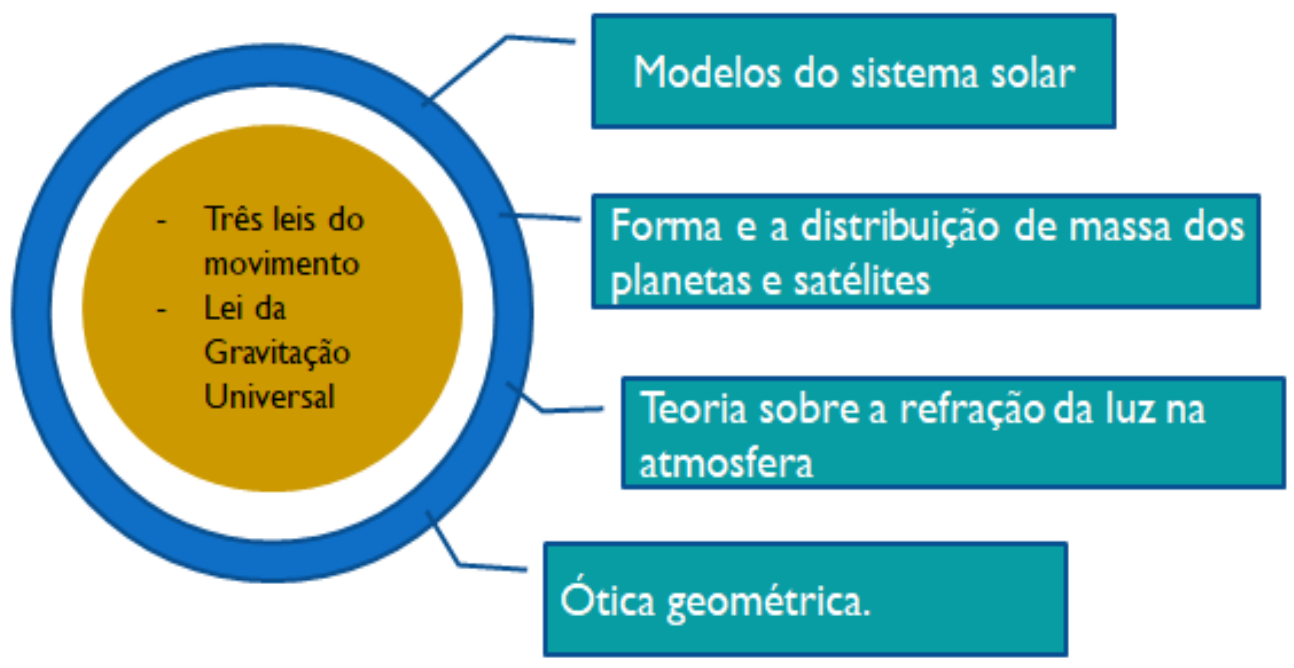

Fonte: Autor

Em situação de discordância, como foi o caso da órbita prevista para Urano, os pesquisadores do programa de Newton não consideram que o núcleo pudesse ser refutado, atribuíram tal discordância a existência de outro planeta, até então não conhecido, o planeta Netuno. Essas decisões tomadas pelos pesquisadores do programa têm como base um conjunto de regras metodológicas, a heurística. Essa pode ser entendida como a conjunção entre uma heurística negativa, que consiste em regras que nos dizem que direções de pesquisa devem ser evitadas, e uma heurística positiva, que são regras que indicam as direções a serem seguidas (BORGES, 2008).

A heurística positiva de um programa de pesquisa tem um papel fundamental no seu desenvolvimento. Quando cientistas se deparam com fatos incompatíveis com as previsões teóricas - refutações ou anomalias - fazem alterações no "cinturão protetor" para superá-las, orientados pela heurística positiva. 
A heurística positiva consiste num conjunto parcialmente articulado de sugestões ou palpites sobre como mudar e desenvolver as "variantes refutáveis" do programa de pesquisa, e sobre como modificar e sofistificar o cinto de proteção ' refutável ' (Lakatos, 1979; p. 165).

Um programa é avaliado como progressivo quando modificações no "cinturão protetor" levam a novas e inesperadas predições ou retrodições - é "empiricamente progressivo" se pelo menos algumas das novas predições são corroboradas. Quando esses ajustes no "cinturão protetor" apenas explicam os fatos que os motivaram, não prevendo nenhum fato novo, ou, se prevendo fatos novos, nenhum é corroborado, o programa é avaliado como Regressivo.

Um programa é regressivo quando seu crescimento teórico se atrasa com relação ao seu crescimento empírico; isto é, se somente oferece explicações post-hoc de descobertas casuais ou de fatos antecipados e descobertos por um programa rival (Lakatos, 1983; p. 117).

A avaliação de um programa é sempre feita comparando a outro programa, dito programa rival. Nessas avaliações e na competição entre programas de pesquisa é que ocorrem as revoluções científicas. Segundo Lakatos, a revolução científica, constitui-se em um processo racional de superação de um programa por outro. A superação ocorre quando um programa "tem em relação ao seu rival um excedente de conteúdo de verdade, no sentido de que prediz progressivamente tudo o que o seu rival corretamente prediz, e algumas coisas adicionais" (Lakatos, 1989; p. 231).

Como se sucedem as revoluções científicas? Se houver dois programas de pesquisa rivais e um deles progride, enquanto o outro degenera, os cientistas tendem a aderir ao programa progressivo. Esta é a explicação das revoluções científicas (Lakatos, 1989, p.15).

O processo de superação de um programa de pesquisa por outro não é rápida; durante esse período é racional trabalhar em qualquer um dos programas de pesquisa rivais, ou talvez até mesmo em ambos. $O$ avanço do conhecimento científico ocorre pela substituição de programas de pesquisa regressivos por programas de pesquisa regressivos, então, nesse processo sobrevivem as teorias que apresentam excesso de conteúdo corroborado, em relação às anteriores, e que antecipam fatos novos. 


\section{A Lógica do Descobrimento Matemático: Provas e Refutações}

Considerada uma das obras mais importantes de Lakatos, "A Lógica do Descobrimento Matemática: Provas e Refutações", que teve como base sua tese de doutorado, procura evidenciar que a matemática é falível. Além disso, faz uma discussão de como ocorre o desenvolvimento do conhecimento matemático.

Nessa obra, na forma de um diálogo fictício entre professor e alunos é abordada a conjectura de Descartes-Euler - para todo poliedro regular, a relação $V-A+F=2$ - ( $V$ é o número de vértices, $A$ é o número de arestas e $F$ é o número de faces). O professor apresenta uma prova baseada na demonstração de Cauchy. Imagina-se um poliedro oco, se retira uma de suas faces e então é possível a planificação da superfície restante. O interessante e que fundamenta essa demonstração, é que na planificação, mesmo que as faces e arestas sejam deformadas, o número de vértices, arestas e faces não se altera. Após a planificação, faz-se o processo triangularização das faces planificadas por diagonais a partir dos vértices e então, retiram-se esses triângulos um a um, retirando-se:

(i) Uma aresta ou;

(ii) Duas arestas e um vértice.

Ao final desse processo resta-se apenas um triângulo e então verifica-se a igualdade $V-A+F=1$ (um face foi retirada antes da planificação, por isso tem-se 1 e não 2 na igualdade). A figura 3 ilustra esse processo.

Figura 3: Processo de planificação utilizado para verificar que $\boldsymbol{V}-\boldsymbol{A}+\boldsymbol{F}=\mathbf{1}$

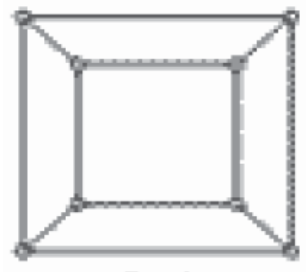

it

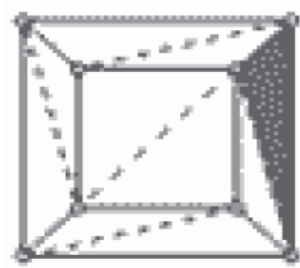

6

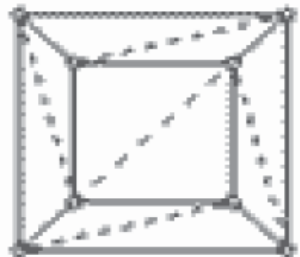

19:

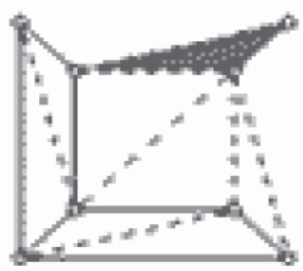

14

Fonte: Lakatos (1976) 
Logo após a apresentação da prova, os alunos participativos e atentos, questionam a validade da relação ao sugerirem contraexemplos, ou seja, poliedros em que a relação $V-A+F=2$ não é válida. Na figura 4 tem-se um desses contraexemplos.

Figura 4: Um contraexemplo à conjectura de Descartes-Euler

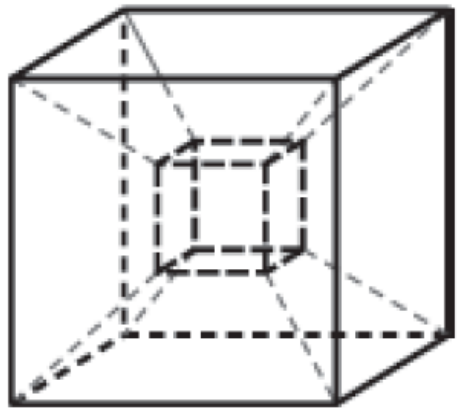

Fonte: Lakatos (1978, p.35)

Esses contraexemplos não invalidam a relação de Descartes-Euler, mas provoca a necessidade da definição de quais poliedros satisfazem essa relação, para os quais a prova é valida. Um contraexemplo, quando se tem uma prova, talvez não invalide um teorema e toda sua teoria, mas deve-se verificar o que esse contraexemplo está dizendo. Uma alternativa é dividir a prova em lemas e verificar se esse contraexemplo não está invalidando algum desses lemas. Com isso não se perde a teoria toda e ainda, é possível melhorá-la.

Molina (2001) traz uma síntese dos estágios propostos por Lakatos no processo de descobertas matemáticas. Essa síntese é apresentada no quadro 1.

Quadro 1: Síntese dos estágios no processo de descobertas matemáticas
(1) Apresenta-se uma conjectura primitiva.
(2) Prova (nesse caso a prova é um argumento mental ou aproximado, que decompõe uma conjectura primitiva em subconjecturas ou lemas).
(3) Surgem contra exemplos globais.
(4) Reexamina-se a prova: identifica-se um lema que foi refutado pelo contra exemplo global, então pode acontecer que: (i) este lema culpável tenha permanecido oculto ou (ii) não tenha sido identificado corretamente. Dessa forma ele é explicitado e incorporado como condição às hipóteses da conjectura primitiva. Isso faz com que a conjectura primitiva seja melhorada, enriquecendo seus conceitos.
(5) Examinam-se provas de outros teoremas para determinar se o lema descoberto aparece neles ou se 0 conceito gerado pela prova aparece neles.
(6) Comprovam-se as consequências da conjectura melhorada.

Fonte: Molina (2001) 


\section{Aproximações das concepções lakatosianas com o ensino de matemática}

Muitos autores têm buscado na filosofia da ciência fundamentação teórica para estudos utilizando diversas concepções metodológicas. Após fazer diversas procuras por trabalhos que relacionem as teorias de Lakatos com a Educação Matemática, buscas essas feitas na internet, Google Acadêmico e Portal de Periódicos CAPES, foram encontrados uma gama considerável de trabalhos. Nesse trabalho, serão abordados três trabalhos evidenciam aproximações com as concepções lakatosianas.

No primeiro trabalho, de Silva e Moura (2015), os autores procuram evidenciar pontos de convergência e divergências entre a metodologia de Investigação Matemática e as concepções da obra "A Lógica do Descobrimento Matemática: provas e refutações". Os pontos de aproximações estão intimamente relacionados com o fato de que a investigação matemática procura colocar os alunos como pesquisadores profissionais em matemática na tentativa da construção do conhecimento, há uma ênfase na atividade matemática.

$\mathrm{Na}$ obra de Lakatos e na metodologia pedagógica de investigação matemática, a atividade matemática em si é fortemente destacada, seja na busca e refinamento de novas teorias, ou na apropriação de conteúdos matemáticos em situações escolares (Silva e Moura, 2015, p.288).

Outros pontos de convergências destacados pelos autores são: o processo de experimentação ingênua da hipótese (ou procura por regularidades) e o diálogo constante. Na procura por regularidades, em investigação matemática, possibilita aos alunos formularem conjecturas, e quando questionados pelo professor ou pelos colegas, utilizam o diálogo para justificar seus achados. Segundo Ponte, Brocardo e Oliveira (2006), este processo propicia aos estudantes um entendimento sobre o significado de investigar, desenvolvem a capacidade de comunicar-se matematicamente, de refletir sobre seu trabalho e sobre o poder da argumentação.

Ainda nesse aspecto, os autores destacam que a valorização das ideias dos estudantes é característica em ambas as concepções.

Em Provas e Refutações, o professor discutia todos os contraexemplos apresentados pelos estudantes, não importando o posicionamento dos mesmos em relação à conjectura exposta. Quando se trabalha com investigações matemáticas em sala de aula, o professor valoriza os posicionamentos e ideias dos estudantes. Isso auxilia no desenvolvimento da autonomia de seus alunos (Silva e Moura, p. 289). 
Os autores destacam alguns pontos de divergências, sendo o mais evidente deles o fato de Lakatos não ter preocupações pedagógicas com a matemática, já o método de investigação matemática é por si só um método pedagógico. Outro ponto de divergência está no processo de refutação, enquanto na obra de Lakatos a demonstração é utilizada no início do processo, em investigação matemática a demonstração (generalização), em geral, é o processo final da tarefa, após diversas discussões e reflexões entre os estudantes (Silva e Moura, 2015).

No segundo trabalho, de Wichnoski e Klüber (2015), a metodologia de investigação matemática é considerada como um programa de pesquisa científico conforme descrito por Lakatos.

Ante a questão investigada, a síntese a que chegamos é que o programa de pesquisa Investigação Matemática, assume em seu núcleo firme a matemática, o ensino, a aprendizagem, a comunicação e atividades investigativas. Em seu cinturão protetor, assume a Educação Matemática e consequentemente a antropologia, a filosofia, a psicologia, a sociologia, bem como a pluralidade e a interdisciplinaridade existente com outras tendências para o ensino de matemática e as teorias e perspectivas de Investigação Matemática que pairam na comunidade de Educação Matemática (Wichnoski e Klüber, 2015, p. 78).

Os autores consideram a investigação matemática como um programa de pesquisa, pois há produção específica sobre o assunto a mais de 20 anos, no âmbito nacional e internacional. Destacam que o programa apresenta um número significativo de anomalias, mas que isso poderá auxiliar corroborando com a construção do programa de pesquisa.

O que deve nos servir de alerta é que diante dessas anomalias, os elementos que compõem o cinturão protetor nem sempre são suficientes para explicá-las ou refutá-las, solicitando que outros elementos sejam incorporados a ele, grosso modo, o cinturão protetor da Investigação Matemática não está fortalecido (Wichnoski e Klüber, 2015, p. 79).

Por considerar a investigação matemática como um programa de pesquisa recente, os autores entendem ser aceitável essas mudanças no cinturão protetor. Essas mudanças poderão ocorrer a longo ou médio prazo, mas com período limitado, pois o programa poderá entrar em estagnação, ou regressão. Os autores reforçam que essas mudanças dependem de pesquisas teóricas envolvendo investigação matemática.

Por fim, o trabalho de Rosa e Orey (2014) caracterizam a etnomatemática como um programa de pesquisa científico, com núcleo firme, cinturão protetor e 
heurísticas bem definidos. Esse programa pode ser definido como o estudo das técnicas que, durante a evolução dos diversos grupos culturais, permitiu que os seus membros pudessem explicar, entender e lidar com os ambientes natural, social, político, econômico e cultural (Rosa e Orey, 2014).

No Brasil, um autor referência para a etnomatemática, D’Ambrosio (1993), diz que a etnomatemática é um programa de pesquisa no sentido lakatosiano, pois a metodologia desse programa é ampla, focalizando a geração, produção, organização, transmissão e difusão do conhecimento desenvolvido pelos membros de grupos culturais distintos, que foram acumulados no decorrer da história e que estão em permanente evolução. A etnomatemática considera os fatores culturais e sociais no ensino de matemática como fundamentais para o seu desenvolvimento. A Figura 5 mostra a etnomatemática como um programa de pesquisa lakatosiano.

Figura 5: A etnomatemática como um programa de pesquisa lakatosiano

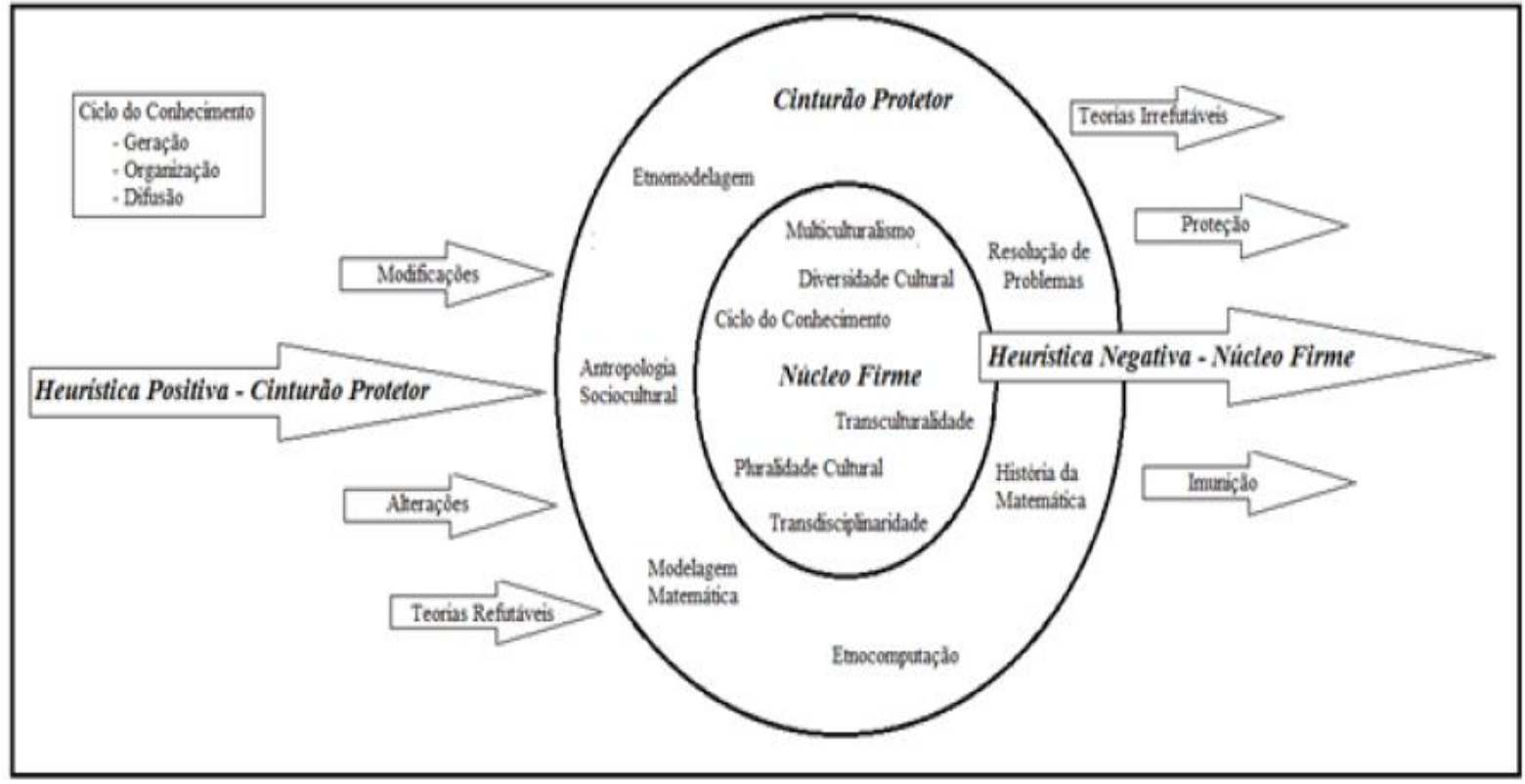

Fonte: Rosa e Orey, (2014).

\section{Considerações Finais}

Imre Lakatos foi um dos principais filósofos e epistemólogos de século XX. Suas principais obras "Metodologia dos Programas de Pesquisa Científica" e "A Lógica do Descobrimento Matemático: Provas e Refutações" foram e ainda são 
fundamentais para o desenvolvimento da ciência. A primeira estabelece os critérios de como ocorrem as revoluções científicas, evidenciando como que um programa de pesquisa cientifico, dito progressivo, supera outro programa de pesquisa científico que está regressão. A segunda traz a concepção de que a matemática é passível de falha e que está constante evolução.

Lakatos não teve uma preocupação com o desenvolvimento pedagógico da matemática. No entanto, cada vez mais, são encontrados trabalhos que enfatizam as relações com suas concepções. Nesse trabalho foi possível apresentar três aproximações com o ensino de matemática. Duas com a metodologia de ensino de investigação matemática: $1^{\text {an}}$ ) foi possível evidenciar as similaridades com os processos da obra "A Lógica do Descobrimento Matemático: Provas e Refutações" e $2^{a}$ ) como um programa de pesquisa científico lakatosiano. Na terceira é caracterizado a etnomatemática como um programa de pesquisa lakatosiano, com núcleo firme, cinturão protetor e heurísticas bem definidas.

Muito ainda é preciso ser estudado para que seja possível fazer melhores aproximações (outras aproximações) e que essas pesquisas possam ter efeitos positivos na sala de aula. O ensino de matemática necessita de mudanças, muitas pesquisas têm sido desenvolvidas nos últimos anos, mas muito ainda precisa ser feito para que esses resultados cheguem ao público alvo: os alunos.

\section{Referências}

ALVES, M. A.; TATSCH, K. J. S. Epistemologia, história e ensino da matemática: reflexões sobre formação e aprendizagem significativa. REnCiMa, v. 8, p. 78-93, 2017. https://doi.org/10.26843/rencima.v8i3.1258

ANASTASIOU, L. G. C. Processos de ensinagem na universidade. Joinville: Univille, 2005.

BORGES NETO, J. Imre Lakatos e a Metodologia dos Programas de Investigação Científica. Curitiba: UFPR, 2008.

D'AMBROSIO, U. Etnomatemática: um programa. A Educação Matemática em Revista, 1(1), p. 5-11, 1993. 
FERREIRA, R.; MOROSINI, M. Metodologias ativas: as evidências da formação continuada de docentes no ensino superior. Revista Docência do Ensino Superior, Belo Horizonte, v. 9, e002543, 2019. https://doi.org/10.35699/2237-5864.2019.2543.

LAKATOS, I. Proofs and refutations. Cambridge: Cambridge University Press, 1976.

A Lógica do descobrimento Matemático: Provas e refutações. Rio de Janeiro, Zahar, 1978.

O falseamento e a metodologia dos programas de pesquisa científica. In: LAKATOS, I. e MUSGRAVE, A. (org.) A crítica e o desenvolvimento do conhecimento. São Paulo: Cultrix, 1979.

History of science and its rational reconstructions. In: HACKING, I. (org.) Scientific revolutions. Hong-Kong: Oxford University, 1983.

La metodología de los programas de investigación científica. Madrid: Alianza, 1989.

MOLINA, J. A. Lakatos como filósofo da Matemática. Episteme. Porto Alegre, n.13, p.129-153, jul/dez/2001.

PONTE, J. P.; BROCARDO, J.; OLIVEIRA, H. Investigações Matemáticas na sala de aula. Coleção Tendências em Educação Matemática. Belo Horizonte: Autêntica, 2006, $152 \mathrm{p}$.

ROSA, M.; OREY, D. C. APROXIMAÇÕES DA ETNOMATEMÁTICA COM O PROGRAMA DE PESQUISA DE LAKATOS. Encontro de Etnomatemática do Rio de Janeiro-Niterói, p. 190-198, 2014.

SILVA, G. H. G. da; MOURA, A. Q. O falibilismo de Lakatos e o trabalho com investigações matemáticas em sala de aula: possíveis aproximações. Acta Scientiae, Canoas, v. 17, n. 2, p. 277-293, maio/ago. 2015.

SILVEIRA, F. L. da. A metodologia dos programas de pesquisa: a epistemologia de Imre Lakatos. Caderno Catarinense de Ensino de Física, v.13, n.3, 1996.

WICHNOSKI, Paulo; KLÜBER, Tiago Emanuel. Um olhar Lakatosiano sobre a tendência investigação matemática. REVEMAT. Florianópolis (SC), v.10, n. 1, p. 6580, 2015. 